\title{
O papel da robótica no desenvolvimento do raciocínio matemático em educação pré-escolar
}

\section{The impact of robotics in the development of mathematical reasoning in pre-school education}

\author{
Ana Cavaco, João Rosa \\ Escola Superior de Educação de Lisboa
}

\begin{abstract}
Resumo
O objetivo do estudo é verificar o impacto de uma intervenção específica em robótica, no desenvolvimento do raciocínio matemático, por crianças pré-escolares. No presente estudo, estiveram envolvidas dezoito crianças de um jardim de infância público, na área de Lisboa, Portugal, com idades compreendidas entre os quatro e os seis anos, alocadas em dois grupos, de intervenção e de controlo.

A análise estatística dos resultados evidenciou que as crianças dos dois grupos eram equivalentes em todas as variáveis, no pré-teste. Essa equivalência manteve-se no pós-teste, à exceção da variável raciocínio matemático, em que as crianças do grupo de intervenção obtiveram resultados significativamente superiores aos do grupo de controlo. Propõe-se que, devido às frequentes operações numéricas envolvidas na montagem e programação de robôts, isso tenha um impacto significativo no desenvolvimento dessas competências.
\end{abstract}

Palavras chave: Robótica em educação pré-escolar, Raciocínio matemático, Robótica Educativa.

\section{Abstract}

This study aims to assess the impact of a specific intervention based on the use of robotics on the development of mathematical reasoning by preschool children.

The participants were 18 , four- to six-year-old children, attending a state run kindergarten, in the Lisbon area, in Portugal. They were allocated to intervention and control conditions.

Statistical analyses showed that both groups were equivalent in all dependent variables, at pre-test. Similarly, post-test measures did not differ, except for mathematical reasoning, where children in the intervention group outperformed, significantly, control children.

This study suggests that the activities of assembling and programming robots demand the frequent use of numerical operations and, eventually, those have a specific impact on children's mathematical reasoning.

Keywords: Robotics in pre-school education, Mathematical reasoning, Educational Robotics.

Este trabalho foi desenvolvido no âmbito da Prática Profissional Supervisionada no Mestrado em Educação Pré-escolar da Escola Superior de Educação de Lisboa.
O objetivo do estudo é verificar o impacto de uma intervenção específica em robótica, no desenvolvimento do raciocínio matemático, por crianças pré-escolares de um jardim de infância público, na área de Lisboa, que integra o programa de Territórios Educativos de Intervenção Prioritária (TEIP).

A zona na qual se situa é urbana e é caracterizada por habitação social e algumas atividades económicas relacionadas com pequeno comércio e serviços. Segundo o Projeto Educativo do Agrupamento (2013/2016), a população servida por esta escola é oriunda de diversas regiões do país e do estrangeiro, nomeadamente dos Países Africanos de Língua Oficial Portuguesa (PALOP), possui tipicamente a escolaridade obrigatória, e o meio social é caraterizado como "heterogéneo e desenraizado" (p.9).

\section{Revisão de literatura}

Os recursos tecnológicos fazem parte da vida de todas as crianças, quer em momentos de lazer se nos referirmos a brinquedos tecnológicos, como computadores, televisores, entre outros, quer no quotidiano se nos referirmos a aquecedores, secadores de cabelo, códigos barras, etc. No JI ou noutro local da comunidade, o acesso ao computador é um meio privilegiado "na recolha de informação, na comunicação, na organização, no tratamento de dados, etc." (Silva, Marques, Mata e Rosa (2016, p.93), possibilitando "aprendizagens, não só no âmbito do conhecimento do mundo, como também nas linguagens artísticas, na linguagem escrita, na matemática, etc." (Silva et al., 2016, p.93). Importa por isso, contribuir para uma maior igualdade de oportunidades, uma vez que o acesso que as crianças têm a estes meios pode ser muito diverso, e auxiliá-las a compreender as potencialidades e riscos das tecnologias, para que se saibam defender.

Os primeiros trabalhos desenvolvidos com robótica na educação foram iniciados por Papert em 1980 no Laboratório de Inteligência Artificial do Massachusetts Institute of Technology (MIT). Durante as suas experiências percebeu que o computador atraía as crianças e que isso poderia facilitar o processo de aprendizagem. Johnson (citado por Oliveira, 2013) 
considera que os robôs para além de educacionais, são "edutainment", ou seja, as crianças podem ser educadas ao mesmo tempo que se divertem, uma vez que o ato de aprender se torna numa atividade agradável. Segundo Alimisis (2009), a robótica educativa pode ser classificada de duas formas de acordo com o papel que desempenha no processo de aprendizagem: como ferramenta ou como objeto de aprendizagem. A robótica é considerada ferramenta de aprendizagem, quando o robô é proposto como uma ferramenta para o ensino e aprendizagem de outras áreas de conteúdo, tais como a matemática ou as ciências. E é considerada objeto de aprendizagem, quando o seu foco está relacionado diretamente com a robótica em si, como a construção do robô, a programação e a inteligência artificial.

Para Ribeiro, Coutinho e Costa (2011) a robótica proporciona a aprendizagem de conhecimentos através da prática, da experiência e de desafios, reunindo "todas as condições para proporcionar um conjunto de atividades interdisciplinares que promovem uma aprendizagem transversal" (p.441). Os robôs têm sido utilizados em vários níveis de ensino, desde o ensino básico ao ensino superior. Em Portugal, foram realizados estudos no Jardim de Infância, tais como o projeto $A$ Casa da Mosca Fosca onde através da programação e encenação da história da Mosca Fosca os robôs foram utilizados como ferramenta para "trabalhar as várias áreas de conteúdo definidas pelo Ministério da Educação para a Educação Pré-Escolar" (Santos, Morgado \& Cruz, 2012, p.42).

Uma característica importante da robótica é a valorização do trabalho em grupo, o que, no pré-escolar é extremamente importante, pois permite trabalhar a área da Formação Pessoal e Social que integra todas as outras áreas e que otimiza a forma como as crianças se relacionam com os outros e com o mundo. Assim, a robótica educativa deve ser vista como uma ferramenta para criar destrezas essenciais para a vida a nível do desenvolvimento pessoal, cognitivo e do trabalho em equipa, através das quais as crianças podem desenvolver o seu potencial usando a imaginação e exprimindo-se.

\section{Metodologia}

Os participantes foram dezoito crianças, oito do sexo masculino e dez do sexo feminino. A sua idade média era de 58,5 meses $(d p=7,5)$. O valor mínimo da idade era de 47 meses e o máximo, de 70 meses. Uma das crianças apresentava Necessidades Educativas Especiais já diagnosticadas e uma outra aguardava um diagnóstico. Eram atendidas numa sala criada de urgência para dar resposta às crianças que se encontravam em lista de espera para serem admitidas na rede pública.

Utilizou-se um design típico de um estudo de intervenção, de natureza quantitativa. As dezoito crianças da sala foram divididas em dois grupos, o grupo de intervenção $(\mathrm{N}=9)$ que manifestou interesse em saber mais sobre robôs e o grupo de controlo $(\mathrm{N}=9)$ que não se interessou particularmente por esse projeto.

É relevante salientar que a ideia para a realização de um projeto com robôs partiu de uma questão colocada por uma criança e isso desencadeou a realização de um projeto segundo a Metodologia de Trabalho por Projeto.

Para avaliar o impacto da intervenção, todas as crianças realizaram um pré-teste e um pós-teste, igual nos dois momentos, desenvolvido expressamente para este estudo. As variáveis dependentes mediam competências básicas usualmente trabalhadas no jardim de infância, nomeadamente a identificação de letras, a nomeação de figuras e de cores, competências grafo-percetivas e raciocínio matemático.

Partia-se da hipótese de que pudesse existir um efeito específico da intervenção no desenvolvimento do raciocínio matemático das crianças dado o tipo de operações cognitivas que a programação e montagem de robôs implica e que esse efeito não se generalizaria às restantes variáveis, usualmente trabalhadas com todas as crianças, pelos educadores de infância. A variável independente era o grupo (de intervenção ou de controlo). Recolheram-se ainda elementos acerca da escolaridade, profissão e idade dos pais.

A intervenção foi conduzida pela investigadora, ao tempo estagiária do curso de Mestrado em Educação Pré-escolar, na sala de atividades, individualmente ou com pequenos grupos. Enquanto decorria a intervenção, a educadora titular conduzia as atividades normais com as restantes crianças.

Os procedimentos da intervenção envolveram o uso de um kit robótico da LEGOß Education denominado WeDo 2.0 que foi concebido a pedido do Ministério da Educação alemão para utilização no $1^{\circ}$ Ciclo do Ensino Básico. A LEGO ${ }^{\circledR}$ Education desenvolve recursos educacionais físicos e digitais que incentivam os alunos a pensar criativamente e a moldar o seu próprio futuro (LEGO, 2017). O kit WeDo 2.0 foi desenvolvido para envolver e motivar as crianças a aprender conteúdos relacionados com as áreas das Ciências e da Engenharia, utilizando modelos motorizados LEGO® e programações simples. O WeDo 2.0 é uma solução de aprendizagem investigativa que fornece às crianças "a confiança de fazerem perguntas, e as ferramentas para encontrarem as respostas e resolverem problemas do quotidiano" (LEGO, 2016, p.4). As crianças aprendem a fazer perguntas e a resolver problemas, uma vez que o kit não lhes dá todas as informações que necessitam. Pelo contrário, instiga a questionar o que já sabem e a procurar respostas sobre o que precisam de saber (LEGO, 2016).

O kit WeDo 2.0 é composto por diversas peças LEGO® coloridas, um motor, um sensor de ultrassom, um giroscópio e um brick e necessita de um computador ou tablet que suporte o respetivo software, para ser programado. A programação é baseada na linguagem de programação LOGO concebida de modo a que as crianças sejam capazes de conseguir que o computador faça algo que elas desejam (Papert, 1996). Desta forma, a linguagem de programação é caracterizada por símbolos que correspondem a componentes do robô e que combinados entre si resultam em ações. Uma vez que, o WeDo 2.0 foi desenvolvido para crianças com idade superior a sete, houve o cuidado de adaptar as estratégias à faixa etária do grupo.

O projeto seguiu um conjunto de etapas sumariadas na tabela 1. 
Tabela 1.

Etapas de desenvolvimento do projeto

\begin{tabular}{cc}
\hline Etapa & Atividade \\
\hline I & Desenho da conceção de robô \\
\hline II & $\begin{array}{c}\text { Exploração do WeDo } 2.0 \text { e montagem da } \\
\text { conceção de robô }\end{array}$ \\
\hline III & Exploração do kit com as famílias \\
\hline IV & Exploração da programação em papel \\
\hline V & Jogo "Agora eu sou um robô" \\
\hline VI & Montagem do robô escolhido pelo grupo \\
\hline VII & Programação do robô \\
\hline
\end{tabular}

Foi inicialmente pedido às crianças que, num desenho, representassem aquilo que para cada uma delas era um robô, quais as características que tinha e como é que se parecia. Nos nove desenhos, foi possível verificar que quase todos os robôs se assemelhavam à figura humana $\mathrm{e}$ que tinham olhos, pois de outra forma "não podiam ver". De seguida, e tendo em conta que, à data, o Plano Anual de Atividades referia a necessidade de desenvolver conhecimentos sobre o corpo humano, foi trabalhada uma analogia entre alguns órgãos/partes do corpo humano e os constituintes do robô. As crianças discutiram essa analogia, tendo concluído pela existência de diversas semelhanças, tal como a tabela seguinte resume.

Tabela 2.

Analogia ente os órgãos do corpo humano e os constituintes do robô

\begin{tabular}{llll}
\hline $\begin{array}{c}\text { Órgãos do corpo } \\
\text { humano }\end{array}$ & $\begin{array}{c}\text { Constituintes } \\
\text { do robô }\end{array}$ & \multicolumn{1}{c}{ Função } \\
\hline Olhos & $\begin{array}{l}\text { Sensor } \\
\text { ultrassom }\end{array}$ & de & $\begin{array}{l}\text { Ver/evitar } \\
\text { obstáculos }\end{array}$ \\
\hline Pernas e braços & Motor e rodas & Movimentar-se \\
\hline Cérebro & Brick & $\begin{array}{l}\text { Processar } \\
\text { informação }\end{array}$ \\
\hline
\end{tabular}

Desta forma, foi possível que as crianças estabelecessem uma correspondência entre as funcionalidades dos constituintes do robô e as funcionalidades de alguns órgãos do corpo humano, tornando-se mais percetível a função de cada constituinte.

Após a elaboração dos desenhos e do exercício de analogia com o corpo humano, o grupo teve oportunidade de explorar as peças do WeDo 2.0, de modo a perceberem as suas formas e cores e a construírem um robô tridimensional, passando as ideias que tinham posto no desenho para um brinquedo que poderiam utilizar nas suas brincadeiras. Alguns pais também estiveram na sala desenvolvendo essa exploração com os seus filhos. Quando as crianças iniciaram as montagens dos robôs, em pequeno grupo, fizeram-no de forma autónoma, dialogando entre si e ajudando-se quando surgiam dificuldades.

De modo a iniciar a programação do robô, foram impressos símbolos da mesma, para que as crianças os pudessem explorar e descodificar. Também para isso, realizaram o jogo "Agora eu sou um robô" em que era dada uma indicação à criança e ela tinha de a executar e de seguida fazer a programação dessa indicação, por exemplo, andar para a frente e voltar para trás. Depois, a pares, as crianças davam instruções aos colegas e estes tinham de as realizar, fingindo que eram robôs a executar a tarefa para a qual tinham sido programados.

Foi ainda pedido às crianças que voltassem a representar através do desenho, aquilo que para elas era um robô, pois já tinham reparado que o robô que entretanto tinham construído não era igual aos seus desenhos iniciais. Foi possível perceber as alterações da sua conceção de robô, pois passaram a desenhá-lo com rodas em vez de ter pernas.

As atividades aqui descritas desenrolaram-se ao longo de dois meses.

\section{Resultados}

A análise estatística dos dados foi realizada através do programa IBM SPSS Statistics, V. 23.

A fim de definir que tipo de testes se deveria utilizar nas análises de significância das diferenças de médias, começou-se por realizar uma análise da assimetria das variáveis dependentes, nos pré- e pós-testes (Howitt \& Cramer, 1997).

Encontraram-se variáveis significativamente enviesadas ( $\mathrm{z}>1.96)$, a saber, identificação de letras, e nomeação de figuras e cores. As restantes variáveis apresentavam uma distribuição normal. Por essa razão usaram-se testes não paramétricos no primeiro caso (Mann-Whitney U) e paramétricos (t-testes), nos restantes, ambos para grupos independentes, analisando-se assim a significância das diferenças de médias em função do grupo.

A tabela 3, mostra, agora, as médias e desvios padrão das variáveis dependentes, nos pré- e pós-testes, nos grupos de intervenção e de controlo.

Tabela 3.

Médias (e desvios padrão), nos pré e pós-testes, em função do grupo

\begin{tabular}{llcl}
\hline \multicolumn{1}{c}{$\begin{array}{c}\text { Variáveis } \\
\text { Dependentes }\end{array}$} & $\begin{array}{c}\text { Grupo de } \\
\text { controlo }\end{array}$ & $\begin{array}{c}\text { Grupo de } \\
\text { Intervenção }\end{array}$ \\
\hline Identificação de de & Pré-teste & 3,00 & 5,55 \\
Letras & Post-teste & $(2,87)$ & $(5,50)$ \\
& & 3,22 & 6,56 \\
& & $(3,19)$ & $(6,93)$ \\
\hline Nomeação de cores & Pré-teste & 12,00 & 11,55 \\
figuras e corest-teste & $(1,66)$ & $(3,05)$ \\
& & 13,33 & 12,00 \\
& & $(0,71)$ & $(3,28)$ \\
\hline Competência & Pré-teste & 5,56 & 7,33 \\
grafo-percetiva & Post-teste & $(2,60)$ & $(1,94)$ \\
& & 7,56 & 8,78 \\
& & $(1,94)$ & $(1,39)$ \\
\hline Raciocínio & Pré-teste & 4,77 & 8,56 \\
matemático & Post-teste & $(3,03)$ & $(5,41)$ \\
& & 9,11 & 15,56 \\
& & $(3,69)$ & $(8,34)$ \\
\hline
\end{tabular}

A tabela sugere que houve alguns progressos, para os dois grupos, entre o pré-teste e o pós-teste, em todas as variáveis. Estes progressos refletem, provavelmente, o desenvolvimento normal dos conhecimentos das crianças à medida que a sua idade aumenta e se desenrolam as atividades no jardim de infância. 
A análise da significância das diferenças de médias, através dos testes paramétricos e não-paramétricos acima referidos, revelou que os dois grupos não eram significativamente diferentes $(p>.05)$ em todas as medidas, no pré-teste e no pós-teste, à exceção de raciocínio matemático. Nesta última variável, apesar de o grupo de intervenção estar melhor no pré-teste, essa diferença não era significativa $\left(\mathrm{t}_{(16)}=-1,83, \mathrm{p}=.09\right)$. No entanto, no pós-teste, as crianças que tinham realizado o projeto dos robôs, desenvolveram significativamente mais a sua competência de raciocínio matemático $\left(\mathrm{t}_{(16)}=\right.$ $-2,12, p=.05)$ quando comparadas com o grupo de controlo.

Não foram encontradas quaisquer correlações significativas entre os resultados das crianças e as habilitações, profissões e idade dos pais.

\section{Conclusão e discussão dos resultados}

Porque a intervenção decorreu na sala de atividades não é possível excluir que algumas aprendizagens mais específicas relativas ao projeto dos robôs tenham passado também para as crianças do grupo de controlo. De facto, e respeitando o contexto naturalístico da sala, as crianças do grupo de intervenção partilharam com o grande grupo as descobertas que iam fazendo e as aprendizagens que iam realizando. Isso permitiu que todo o grupo acompanhasse a progressão do trabalho e que compreendesse o que se estava a desenvolver.

A análise estatística dos resultados evidenciou, contudo, que não eram as diferenças de partida que poderiam explicar resultados diferentes no pós-teste. Nem existiam diferenças de partida nem as crianças do grupo de intervenção progrediram mais em variáveis normalmente trabalhadas. Este padrão sugere que a intervenção teve um efeito específico.

Pensamos que este resultado pode dever-se ao facto de as crianças do grupo de intervenção realizarem numerosas operações numéricas durante a montagem e programação dos robôs, uma vez que tanto a medida das peças necessárias à sua construção ou a sua quantidade, bem como o tempo que o robô leva para andar ou a velocidade do mesmo e ainda a sequenciação das operações de programação exigem a manipulação de variadas noções numéricas. Conclui-se que a construção, programação e interação com robôs em projetos desenvolvidos com as crianças no pré-escolar pode ser um bom instrumento para potenciar o seu raciocínio matemático. Queremos, no entanto, ressalvar, que esta conclusão tem um caráter exploratório e carece de ser replicada em estudos que envolvam um maior número de crianças e de salas de jardim de infância, à semelhança dos trabalhos que estão, presentemente, a ser desenvolvidos em Portugal (Miranda-Pinto, 2016).

\section{Referências}

Alimisis, D. (2009). Teacher Education on Robotics-Enhanced Constructivist Pedagogical Methods. Athens: School of Pedagogical and Tecnological Education (ASPETE).

LEGO, G. (2016). LEGO Education WeDo 2.0: Projetos Curriculares. Manuscrito não publicado.
LEGO, G. (2017). LEGO Education. Consultado a 1 de fevereiro de 2017, em https://education.lego.com/ en-us/about-us

Miranda-Pinto, M. (2016). Program with scratch Jr in preschool: Kids Media Lab project in Portugal. MIT, Media Lab / Cambridge, MA, USA. https://scratch.mit.edu/conference.

Oliveira, D. (2013). A Robótica Educativa no Ensino e Aprendizagem de Conceitos de Programação $e$ Algoritmos. (Dissertação de Mestrado apresentada à Universidade de Lisboa, Lisboa). Consultada em http://repositorio.ul.pt/handle/10451/9892

Papert, S. (1996). A Família em Rede: Ultrapassando a Barreira Digital entre Gerações. Lisboa: Relógio D’Água.

Ribeiro, C., Coutinho, C., e Costa, M. (2011). A Robótica Educativa como Ferramenta Pedagógica na Resolução de Problemas de Matemática no Ensino Básico. In Conferência Ibérica de Sistemas $e$ Tecnologias de Informação (pp. 440-445). Associação Ibérica de Sistemas e Tecnologias de Informação.

Santos, C., Morgado, L., e Cruz, M. (2012). A Casa da Mosca Fosca: Integração de robótica educativa no jardim de infância. CICTFF - Indagatio Didactica, 4(1), 42-58.

Silva, I., Marques, L., Mata, L., \& Rosa, M. (2016). Orientações Curriculares para a Educação Pré-Escolar. Lisboa: Ministério da Educação/ Direção-Geral de Educação (DGE). 